\title{
Neural Correlates of Enhanced Visual Attentional Control in Action Video Game Players: An Event-Related Potential Study
}

\author{
Julia Föcker ${ }^{1}$, Matin Mortazavi ${ }^{1}$, Wayne Khoe ${ }^{2}$, Steven A. Hillyard ${ }^{2}$, and Daphne Bavelier ${ }^{3}$
}

\begin{abstract}
Action video game players (AVGPs) outperform non-action video game players (NAVGPs) on a range of perceptual and attentional tasks. Although several studies have reported neuroplastic changes within the frontoparietal networks of attention in AVGPs, little is known about possible changes in attentional modulation in low-level visual areas. To assess the contribution of these different levels of neural processing to the perceptual and attentional enhancements noted in AVGPs, visual event-related potentials (ERPs) were recorded from 14 AVGPs and 14 NAVGPs during a target discrimination task that required participants to attend to rapid sequences of Gabor patches under either focused or divided attention conditions. AVGPs responded faster to target Gabors in the focused attention condition compared with the NAVGPs. Correspondingly, ERPs to standard Gabors revealed a more pro-
\end{abstract}

\section{INTRODUCTION}

During the past 15 years, a growing body of literature has been documenting the impact of video game play and, in particular, the entertainment video game genre classified as "action video games," on different aspects of cognition. Action video game play is defined in this literature as first- or third-person shooter games such as Medal of Honor or Call of Duty and requires the processing of large amounts of visual information presented rapidly over a wide field of view under highly attention-demanding conditions. As this gaming activity becomes more and more ubiquitous in our society, at stake is our understanding of how it may shape cognition. Mounting evidence supports the hypothesis that action video game experience enhances attentional control (see Chisholm \& Kingstone, 2015; Blacker, Curby, Klobusicky, \& Chein, 2014; Cain, Prinzmetal, Shimamura, \& Landau, 2014; Appelbaum, Cain, Darling, \& Mitroff, 2013; Cain, Landau, \& Shimamura, 2012; Donohue, Woldorff, \& Mitroff, 2010; Dye \& Bavelier, 2010; Green, Pouget, \& Bavelier, 2010; Li, Polat, Makous, \& Bavelier, 2009; Cohen, Green, \&

\footnotetext{
${ }^{1}$ Ludwig-Maximilians-University of Munich, ${ }^{2}$ University of
} California, San Diego, ${ }^{3}$ University of Geneva nounced negativity in the time range of the parietally generated anterior N1 component in AVGPs compared with NAVGPs during focused attention. In addition, the P2 component of the visual ERP was more pronounced in AVGPs than in NAVGPs over the hemisphere contralateral to the stimulus position in response to standard Gabors. Contrary to predictions, however, attentionmodulated occipital components generated in the low-level extrastriate visual pathways, including the P1 and posterior N1, showed no significant group differences. Thus, the main neural signature of enhanced perceptual and attentional control functions in AVGPs appears linked to an attention-dependent parietal process, indexed by the anterior N1 component, and possibly to more efficient higher-order perceptual processing, indexed by the P2 component.
Bavelier, 2007; Green \& Bavelier, 2003, 2007; see Bavelier, Green, Pouget, \& Schrater, 2012, for a review). In behavioral studies comparing action video game players (AVGPs) and non-action video game playing controls (NAVGPs), it has been found that AVGPs perform better in a variety of attention-demanding tasks. In particular, AVGPs excel at identifying peripheral targets among distractors (Chisholm \& Kingstone 2012, 2015; Chisholm, Hickey, Theeuwes, \& Kingstone, 2010; West, Stevens, Pun, \& Pratt, 2008; Green \& Bavelier, 2006a) and exhibit faster visual search rates (Wu \& Spence, 2013; HubertWallander, Green, Sugarman, \& Bavelier, 2011; but see Castel, Pratt, \& Drummond, 2005). AVGPs also exhibit larger attentional capacity as indexed by greater processing of irrelevant flankers at low perceptual loads (Dye, Green, \& Bavelier, 2009; Green \& Bavelier, 2003). Their superior attentional skills are also evident when attending selectively to a target among distractors, whether in time or space (Green \& Bavelier, 2003), and when dividing attention across multiple locations or objects in the visual field (West et al., 2008; Green \& Bavelier, 2006b; Greenfield, DeWinstanley, Kilpatrick, \& Kaye, 1994). These findings lend support to the hypothesis that action video game play enhances top-down attentional control processes (Bavelier \& Föcker, 2015; Green, Sugarman, 
Medford, Klobusicky, \& Bavelier, 2012; Spence \& Feng, 2010). This view is also supported by findings that AVGPs are proficient at change detection (Clark, Fleck, \& Mitroff, 2011) and can more effectively recover from attentional capture (Chisholm \& Kingstone, 2012, 2015; Chisholm et al., 2010).

In addition to these enhanced attentional capabilities, action video game play also has been shown to improve various aspects of visual perception. In comparison with NAVGPs, AVGPs have been found to display greater contrast sensitivity (Li et al., 2009), enhanced acuity under conditions of crowding (Green \& Bavelier, 2007), and reduced backward masking (Li, Polat, Scalzo, \& Bavelier, 2010). AVGPs also showed greater sensitivity than NAVGPs at detecting coherent motion in a random dot kinematogram (Pavan, Boyce, \& Ghin, 2016; Green et al., 2010). These findings suggest a beneficial influence of action gaming experience when accumulating sensory information. A prominent hypothesis in the field is that AVGPs, because of their enhanced attentional control, may learn to develop better perceptual templates for task-relevant features as the task proceeds, a process also known as target matching (Bejjanki et al., 2014).

In contrast to this rather rich behavioral literature (see Bediou et al., 2017 for a meta-analysis), the neural bases of AVGP superiority in perceptual and attentional tasks have only been sparsely investigated. In a study using fMRI, Bavelier, Achtman, et al. (2012) found that the frontoparietal network known to mediate attentional control was recruited to a lesser extent in AVGPs than in NAVGPs as task difficulty and attentional demands increased. This observation was interpreted as indicative of a more automatic allocation of attention in AVGPs, which is consistent with behavioral findings that action game play enhances aspects of top-down attentional control (reviewed in Green \& Bavelier, 2012). Bavelier, Achtman, et al. (2012) also observed greater suppression of neural activity in the mid-level cortical area MT/MST in response to irrelevant moving patches in AVGPs compared with NAVGPs. Similarly, two studies using steady-state visually evoked potential recordings (Krishnan, Kang, Sperling, \& Srinivasan, 2013; Mishra, Zinni, Bavelier, \& Hillyard, 2011) also have documented greater neural suppression of task-irrelevant information in AVGPs. In the study of Krishnan et al. (2013), a correlation was observed between parietal steady-state visually evoked potential amplitudes to unattended stimuli (ignored flicker) and the corresponding hit rate at attended locations in AVGPs. The electrodes showing the highest correlations were over the right parietal and temporal lobes, brain areas proposed to be involved in the monitoring of unattended locations for behaviorally relevant information (see Corbetta, Patel, \& Shulman, 2008). Finally, Wu et al. (2012) compared the impact of $10 \mathrm{hr}$ of training with an action video game versus a control (non-action) video game on visual event-related potentials (ERPs) in a visual search task. They reported a marginally greater positivity in the $\mathrm{P} 2$ component in participants who were trained on the action video game and showed the largest behavioral improvement as a result of their training. The implications of this result are difficult to ascertain, however, given the focus on only those participants who behaviorally benefited the most from the action video game training, as well as the fact that the functional significance and neural generators of the P2 component remain uncertain.

Taken together, the handful of available studies reviewed above point to neuroplastic changes in AVGPs, most likely taking place in higher-level cortical areas such as those encompassing the frontoparietal networks of attention. Yet, they leave unanswered the important question of whether the heightened perceptual and attentional skills of AVGPs may also depend on attentional modulations at low- or mid-level visual areas, such as the striate cortex and/or extrastriate visual pathways in the occipital lobe. This is an important question, considering that enhanced perceptual abilities under attention demanding conditions could in principle arise from very different mechanisms. For example, changes in the efficiency with which higher frontoparietal decision-making and attentional control systems integrate the information available from earlier sensory cortices have been shown to mediate heightened performance (Kahnt, Grueschow, Speck, \& Haynes, 2011; Law \& Gold, 2008; Petrov, Dosher, \& Lu, 2005). Alternatively, enhanced perceptual abilities could also result from more effective processing in low-level sensory areas that gate or amplify perceptual information under attentional selection (Crist, Li, \& Gilbert, 2001; Luck, Chelazzi, Hillyard, \& Desimone, 1997). These two mechanisms are certainly not mutually exclusive and could co-occur (Gilbert \& Li, 2013). Yet, they do make different predictions about the extent to which training-induced brain changes will transfer to influence a wider range of tasks, as elegantly illustrated in the perceptual learning literature (Roelfsema, van Ooyen, \& Watanabe, 2010; Ahissar \& Hochstein, 2004). Indeed, changes in higher frontoparietal areas are more likely to lead to transfer to a greater variety of tasks than are changes in low-level, sensory areas (Harris, Gliksberg, \& Sagi, 2012). Action video game play as an intervention is quite unique because it has been linked not only to heightened perceptual sensitivity, typically associated with low- or mid-level neuroplastic changes (e.g., within areas such as V1 or MT/MST), but also to heightened perceptual transfer, typically associated with neuroplastic changes at higher levels (e.g., within the frontoparietal network; Watanabe \& Sasaki, 2015). Studies of AVGPs therefore have the potential to shed a unique light on the locus of neuroplastic changes that underlie and sustain these two kinds of behavioral impact, which so rarely coexist.

This study aims to elucidate the neural bases of enhanced performance in AVGPs in a visuospatial attention task that requires fine perceptual discriminations by 
examining each of the early components ( $<250 \mathrm{msec}$ ) of the visual ERP to stimuli under different attentional conditions. Previous research (reviewed in Luck \& Hillyard, 2000, 2014; Hopfinger, Luck, \& Hillyard, 2004) has linked these early components to specific aspects of perceptual and/or attentional processing as follows: C1 (latency 65105 msec: initial evoked response in primary visual cortex), P1 (115-160 msec: sensory gain control in early extrastriate visual pathways), posterior N1 (170-215 msec: discriminative processing of target features in extrastriate visual cortex), anterior N1 (125-175 msec: control of spatial focus of attention in parietal cortex), and $\mathrm{P} 2$ (220-270 msec: possibly reflecting overall task demands and target matching). By testing for amplitude differences between AVGPs and NAVGPs in the C1, P1, and posterior $\mathrm{N} 1$ components, we assessed the possibility of gaming-related changes in the striate and extrastriate occipital pathways. In addition, we examined processing differences between the groups in higher cortical areas, in particular the parietal cortex, as manifested in the anterior N1 component; group differences in the P2 component were also examined, although its neural sources and functional significance have yet to be established.

\section{METHODS}

\section{Participants}

A total of 33 right-handed male young adults (age range $=$ 19-28 years, mean $=23, S D=4.3$ ) were classified according to their experience over the past 12 months in playing first-person shooter video games (Brain and Vision Labo- ratory Gaming Questionnaire, University of Rochester). Participants classified as AVGPs $(n=17)$ played a minimum of 3-5 hr per week, with most participants playing more than $5 \mathrm{hr}$ per week as indicated by a weekly mean of $9.0 \mathrm{hr}(S D=2.7)$. NAVGPs $(n=16)$ had no experience playing any type of video game. All participants reported having normal or corrected-to-normal vision and other sensory functions, and each was paid $\$ 15.00 / \mathrm{hr}$ for their participation. The final sample consisted of 14 NAVGPs and 14 AVGPs.

\section{Visual Stimuli}

Figure 1A illustrates the experimental paradigm. Stimuli were presented as gray-level modulations on a 21-in. video monitor at a viewing distance of $100 \mathrm{~cm}$ in a darkened room. During testing, participants fixated a high-contrast central cross $\left(0.5^{\circ}\right.$ of visual angle) on a gray background $\left(1.8 \mathrm{~cd} / \mathrm{m}^{2}\right)$. The task stimuli consisted of $100 \%$ Michelson contrast Gabor patches $\left(\lambda=\sigma=0.44^{\circ}\right)$ having three, six, or nine cycles per degree (cpd) of visual angle. These patches were presented for $33 \mathrm{msec}$ exposures at $6^{\circ}$ lateral to fixation in random order to the left or right visual field at an elevation of $1.5^{\circ}$ above the horizontal meridian. Standard patches presented in the left visual field were rotated clockwise $45^{\circ}$ from the vertical axis, whereas standards in the right visual field were rotated counterclockwise $45^{\circ}$. Target patches were rotated an additional $15^{\circ}$ (either clockwise or counterclockwise) relative to the standard rotation but were otherwise identical to the standards. Gabor phase and spatial frequency were varied randomly across presentations.
Figure 1. (A) Visual stimuli and experimental procedures. At the beginning of each trial, a cue (white arrow, duration $=$ $1500 \mathrm{msec}$ ) indicated the participants to attend to the left side, the right side (focused attention condition), or to both sides (divided attention condition). After an ISI of 1000 msec, visual Gabor patches were presented at an average rate of $3 / \mathrm{sec}$. Mostly standard Gabor patches were presented with those in the left visual field being rotated clockwise $45^{\circ}$ and those in the right visual field counterclockwise $45^{\circ}$. The rare target patches were rotated an additional $15^{\circ}$ from each standard orientation. (B) $d^{\prime}$ to targets in the focused and divided condition as a function of group (NAVGPs vs. AVGPs). (C). RTs to targets in the focused and divided condition as a function of group (NAVGPs vs. AVGPS).

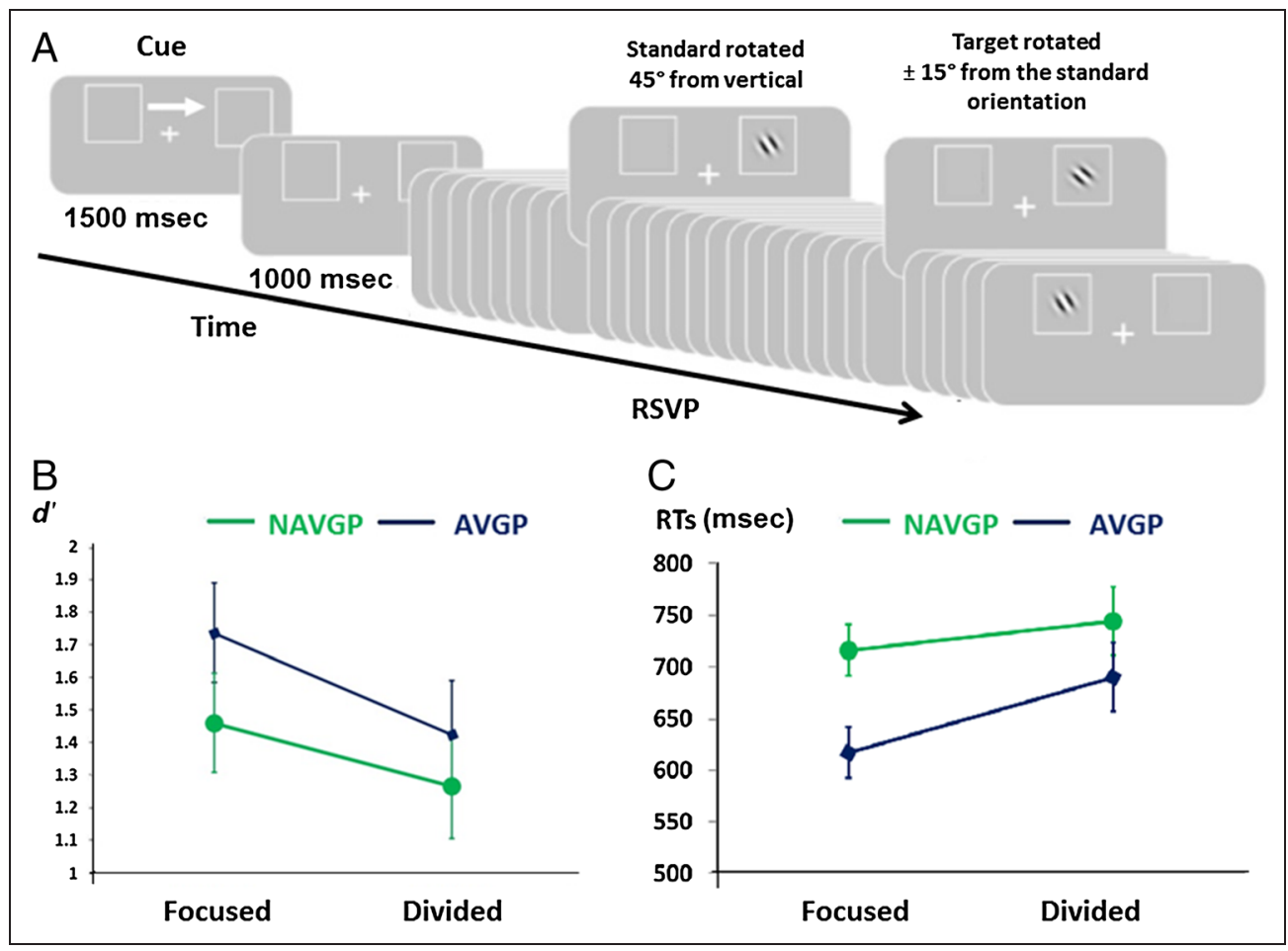




\section{Experimental Design}

At the start of each trial, an arrow cue was presented for $1500 \mathrm{msec}$ that directed the participant's attention to the left, right, or both visual fields. Following a 1000-msec delay, independent sparse sequences of Gabor patches at an average rate of $3 / \mathrm{sec}$ were presented to each visual field. Sparse sequences were used to ensure that each stimulus event was temporally independent of the preceding and subsequent events (James, Ruseckaite, \& Maddess, 2005). For each screen refresh $(30 \mathrm{~Hz})$, the probability of a stimulus presentation was .1 in each visual field.

Participants were informed that single arrow cues predicted the target location with 100\% certainty, whereas a double arrow (i.e., bidirectional cue) indicated that the target could occur with equal probability in either visual field. Targets could occur at any time between 3 and $10 \mathrm{sec}$ from the start of the sequence and were present on $77 \%$ of the trials. If a target did not appear by $10 \mathrm{sec}$, the sequence self-terminated. Participants were instructed to press the spacebar key when a target was detected; responses made within a 1500-msec window after the target were classified as "hits," after which the sequence continued for the remainder of the 1500-msec window. Similarly, the sequence continued for $1500 \mathrm{msec}$ posttarget for "missed" targets. The sequences ended immediately when participants responded to a nontarget, these incorrect responses were classified as "false alarms."

\section{EEG Data Acquisition and Analysis}

Scalp potentials were recorded from 60 tin electrodes mounted in a custom cap that were distributed evenly across the head (Electro-Cap International, Eaton, $\mathrm{OH}$ ), with the electrode labels approximating those of the 10-20 system (Di Russo, Martínez, \& Hillyard, 2003). Scalp and mastoid electrode impedances were maintained below $5 \Omega$. Scalp potentials were referenced to the right mastoid during recording. Vertical eye movements were recorded with an electrode below the left eye and referenced to the right mastoid. Horizontal eye movements were monitored with a bipolar montage between the left and right outer canthi. Scalp recorded activity was amplified with a band pass of 0.1-80 Hz. EOG activity was amplified with a band pass of 0.01-80 Hz. Signals were digitized at a sampling rate of $250 \mathrm{~Hz}$ with a gain of 10,000 .

EEG data were analyzed in Matlab (The MathWorks, Inc., Natick, MA) using the EEGLab/ERPLab toolbox (Lopez-Calderon \& Luck, 2014; Delorme \& Makeig, 2004). The data were first digitally rereferenced to linked mastoids and then bandpass filtered offline with a half amplitude cutoff of $0.1-40 \mathrm{~Hz}$ (noncausal Butterworth impulse response function, $-6 \mathrm{~dB} /$ octave). Three types of epochs were created: ERPs recorded to the onset of the visual standard Gabors were segmented into epochs from -200 to $500 \mathrm{msec}$, ERPs time-locked to the onset of the target Gabors followed by a correct response were segmented from -200 to $800 \mathrm{msec}$ to inspect the target-locked P3, and ERPs time-locked to the onset of a motor response (response-locked P3 - including only correct responses) were segmented from -200 to $600 \mathrm{msec}$. Epochs time-locked to the standard Gabor stimuli were rejected from further analyses if they included a motor response of any kind (Hit or false alarm). All epochs were then baseline corrected using the mean voltage over the 200-msec preevent period.

\section{Artifact Rejection}

Epochs with ocular artifacts were removed by applying the step-like artifact rejection function (window size = $400 \mathrm{msec}$, step size $=50 \mathrm{msec}$, threshold $=20 \mu \mathrm{V}$ ) of ERPLab toolbox (Delorme \& Makeig, 2004) to activity of the VEOG (electrode under the left eye) and HEOG (average of right and left outer canthi electrodes) channels. In addition, any epoch with voltages exceeding $\pm 75 \mu \mathrm{V}$ or a difference between two consecutive data points exceeding $50 \mu \mathrm{V}$ were classified as artifacts and were excluded from further analysis. To achieve a sufficient signal-to-noise ratio for the averaged ERPs, the thresholds of EEG and ocular artifact rejection procedures had to be adjusted (up to \pm 120 and $40 \mu \mathrm{V}$ for EEG and ocular artifact rejections, respectively) for seven participants (three NAVGPs and four AVGPs). Following this adjustment, careful visual inspection of epochs after artifact rejection ensured the absence of artifacts for these participants. The number of epochs including ocular artifacts did not differ between AVGPs and NAVGPs (for standard Gabors: NAVGPs [mean $=1379, S E=172$ ] and AVGPs $[$ mean $=1370, S E=155], t(26)=.037, p=.97$; for target-locked epochs: NAVGPs [mean $=9, S E=2$ ] and AVGPs [mean $=14, S E=3$ ], $t(26)=-1.203, p=.24$; for response-locked epochs: NAVGPs [mean $=22, S E=3$ ] and AVGPs [mean $=28, S E=5$ ] $, t(26)=-1.154, p=.26$ ).

An ANOVA with number of artifact-free trials as the dependent variable was performed including the factors Group (NAVGPs vs. AVGPs) and Attention (Focused vs. Unattended vs. Divided). Importantly, the number of artifact-free trials did not differ between AVGPs and NAVGPs (main effect of Group: $F(1,26)=.48, p=.49$; mean NAVGPs $=383, S E=41$; mean AVGPs $=424, S E=$ 41). There was a main effect of Attention, $F(2,52)=$ $71.37, p<.001$, due to a higher number of artifact free trials as the attentional status of the analyzed stream varied from Divided (mean $=489, S E=37$ ) to Focused $($ mean $=357, S E=25)$ and Unattended (mean $=364$, $S E=26)$; the number of trials under the focused and the unattended attentional status was comparable. The interaction effect between Group and Attention was not significant, $F(2,52)=.7, p=.5$. Finally, the number of artifact free trials was comparable across groups for both target-locked and for response-locked ERPs (target-locked 
P3: mean NAVGPs $=53, S E=7$; mean AVGPs $=59$, $S E=6, t(26)=-.705, p=.49$; response-locked: mean NAVGPs $=43, S E=6$; mean AVGPs $=51, S E=6$, $t(26)=-.913, p=.37$ ).

After artifact rejection, the epochs of each type were averaged separately. Note that every event in these sparse sequences was labeled with a trigger pulse, including not only target and standard Gabors but also points in time where a stimulus could have been presented but was not. The averaged EEG activity time-locked to these nonstimuli was subtracted from the averaged EEG activity time-locked to the Gabor stimuli to increase the signalto-noise ratio of the ERPs. This subtraction removed the overlapping activity of the successive epochs, which can often be substantial in rapid serial visual presentation paradigms (James et al., 2005).

\section{Behavioral Data}

\section{Analyses}

The hit and false alarm rates were used to calculate the target detection sensitivity index $d^{\prime}$ (MacMillan \& Creelman, 1991). As targets were presented within a RSVP stream, the attribution of a target response to a particular preceding target may be ambiguous. Therefore, $d^{\prime}$ was calculated by applying the procedure proposed by Bendixen and Andersen (2013; equation 10). In short, the main issue in RSVP paradigms concerns the computation of the false alarm rate. To this end, Bendixen and Andersen (2013) proposed to first define the length of the interval within which a response is permissible. We set this value to $1500 \mathrm{msec}$, as this was the time window acceptable for a response after a target in our paradigm. For each participant, we then computed the duration of all trials concatenated or what is called the total trial duration (TTD). Note that this value varied for each participant as each individual performed differently in the experimental task. This value divided by the response interval of $1500 \mathrm{msec}$ gives the number of epochs where a response was possible. By subtracting the total number of targets from this latter value, we get the number of epochs where no responses should be given. This value is then used as the denominator to compute the rate of false alarms according to the following formula:

$$
\begin{aligned}
\text { False Alarm (FA) Rate } & \\
= & (\text { Number of FA }) / \\
& {[(\text { TTD } / \text { response interval })-\text { Number of targets }] }
\end{aligned}
$$

The hit rates were then calculated using the conventional hit rate formula (i.e., number of correct responses/number of targets). Finally, the $d^{\prime}$ index was computed for each participant using the following formula: $d^{\prime}=$ Standardized hit rate - Standardized false alarm rate.

RTs were calculated as the interval between the onsets of the target stimuli and the onsets of the correct responses.

\section{ERP Analysis}

For all the ERP analyses, a "collapsed localizer" method was used to find the time window and also the electrode clusters that maximally encompassed the component's peak and immediately surrounding time points (Luck \& Gaspelin, 2017). A consensus of careful visual inspections of grand-averaged waveforms collapsed across all experimental conditions and across all participants (i.e., collapsed localizer) by the experimenters determined the time windows and electrode clusters for each ERP component to calculate mean amplitude measures.

For analyses of ERPs to standard Gabor stimuli, the following components were investigated: C1 (65-105 msec) was analyzed at a midline posterior cluster of electrodes POz, Oz, Iz. There has been a long-standing controversy about whether attention modulates the early C1 component of the visual evoked potential, which represents the initial response of the primary visual cortex (reviewed in Ding, Martínez, Qu, \& Hillyard, 2014; Slotnick, 2013). The majority of studies that have investigated possible influences of attention on the $\mathrm{C} 1$ have found no such effects, and studies that did report C1 modulations have either proven difficult to replicate (Baumgartner, Graulty, Hillyard, \& Pitts, 2017a; Ding et al., 2014) or could be explained by nonattentional factors (Baumgartner, Graulty, Hillyard, \& Pitts, 2017b). Given this state of affairs, we did not expect group differences in $\mathrm{C} 1$.

The P1 component (115-160 msec) was analyzed at a lateral posterior cluster of electrodes $\mathrm{O} 1 / \mathrm{O} 2, \mathrm{PO} 7 / \mathrm{PO} 8$, $\mathrm{I} 3 / \mathrm{I} 4$, and the posterior N1 (170-215 $\mathrm{msec})$ at an overlapping cluster P7/P8, PO7/PO8, I3/I4. The neural sources of the P1 and posterior N1 components have been localized in extrastriate visual cortical areas of the occipital lobe (Di Russo et al., 2003, 2012; Di Russo, Martínez, Sereno, Pitzalis, \& Hillyard, 2002) and are modulated by spatial attention (reviewed in Luck \& Hillyard, 2000, 2014; Hillyard \& Anllo-Vento, 1998). Previous research has suggested that modulations of the P1 and posterior N1 components are associated with different aspects of attentional selection, with $\mathrm{P} 1$ reflecting an early gain control or filtering operation and posterior N1 indexing the discriminative processing of attended location stimuli (Vogel \& Luck, 2000; Luck et al., 1994; Luck, Heinze, Mangun, \& Hillyard, 1990; reviewed in Hopfinger et al., 2004). Given our stated hypothesis, we were expecting group differences in these two components.

The anterior N1 component (125-175 msec) was analyzed at a lateral anterior cluster of electrodes $\mathrm{AF} 3 / \mathrm{AF} 4$, F3/F4, F7/F8, FC5/FC6. The anterior N1 increases with attention (Di Russo et al., 2003, 2012; Luck et al., 1994) and has been localized to the vicinity of the intraparietal sulcus (Di Russo et al., 2002, 2003), which suggests that this component is linked with parietal lobe mechanisms that control the allocation of spatial attention. Its cortical source and presumed function are concordant with previously reported group differences between AVGPs and 
NAVGPs in the few other brain imaging studies published to this date.

The P2 component (220-270 msec) was analyzed at a lateral central cluster of electrodes $\mathrm{C} 3 / \mathrm{C} 4, \mathrm{C} 5 / \mathrm{C} 6, \mathrm{CP} 5 /$ $\mathrm{CP} 6$ ). The $\mathrm{P} 2$ component has been proposed to reflect overall task demands (Fritzsche, Stahl, \& Gibbons, 2011; Potts, Patel, \& Azzam, 2004; Potts, Liotti, Tucker, \& Posner, 1996), but its functional significance in spatial attention tasks remains unclear. For example, Clark and Hillyard (1996) and Di Russo et al. (2003) found no spatial attention effect on the P2, whereas Mangun and Hillyard (1987) and Martínez et al. (2001) found an enhanced negativity with attention that overlaid the P2, making the P2 measure smaller with attention. In contrast, Di Russo et al. (2012) and Luck et al. (1994) found the P2 to be enlarged with attention. In the present experiment, we therefore did not expect the P2 to show a consistent variation under the different attentional conditions, but given its reported increase after only $10 \mathrm{hr}$ of training on an action video game (Wu et al., 2012), we did expect the P2 to be more positive in AVGPs than in NAVGPs.

ERPs to Targets. The target-locked P3 component (500$700 \mathrm{msec}$ ) was measured at a central posterior cluster of electrodes $\mathrm{CPz}, \mathrm{CP} 1, \mathrm{CP} 2, \mathrm{Pz}, \mathrm{P} 1$, and $\mathrm{P} 2$, and the response-locked $\mathrm{P} 3(-50$ to $250 \mathrm{msec})$ at an overlapping posterior cluster of $\mathrm{Pz}, \mathrm{P} 1, \mathrm{P} 2, \mathrm{PO} z, \mathrm{PO} 3$, and $\mathrm{PO} 4$. The $\mathrm{P} 3$ component has been associated with postperceptual processes that underlie the updating of mental representations of task-relevant stimuli (Polich, 2007), postperceptual processes engaged in decision-making (Hillyard \& Kutas, 1983), and the activation of stimulus-response links (Verleger, Hamann, Asanowicz, \& Śmigasiewicz, 2015).

The omnibus ANOVA for the ERP amplitude measures included the between-subject factor Group (AVGPs, NAVGPs), the within-subject factors Attention Status (Attended, Unattended, Divided) and Hemisphere (Ipsi, Contra with respect to the location of the analyzed standard Gabor stimulus-note that there was no hemisphere factor for $\mathrm{C} 1$ given the midline locations of the electrodes considered). Only between-group $t$ tests were carried out for the target-locked and responselocked P3. For all behavioral and ERP statistical analyses, Greenhouse-Geisser corrections to $d f$ were used to counter the violation of sphericity assumption, and post hoc comparisons were run using the Fisher's least significant difference test.

\section{RESULTS}

\section{Behavioral Results}

\section{Target Detection Sensitivity- $d^{\prime}$}

An ANOVA including the within-subject factor Attention (focused versus divided) and the between-subject factor Group (AVGPs vs. NAVGPs) was carried out on $d^{\prime}$ (Figure 1B). It revealed a main effect of Attention, $F(1$,
26) $=17.06, p<.001, \eta^{2}=.4$, with a higher sensitivity in the focused (mean focused $=1.6, S E=0.11$ ) compared with the divided (mean divided $=1.35, S E=0.12$ ) condition, as expected. Neither the main effect of Group nor the interaction between Attention and Group was significant (all $p s>.3$ ).

\section{$R T S$}

The ANOVA on RTs including the within-subject factor Attention (focused vs. divided) and the between-subject factor Group (AVGPs vs. NAVGPs) revealed a main effect of Attention, $F(1,26)=24.95, p<.001, \eta^{2}=.49$, due to shorter RTs in the focused (mean $=670 \mathrm{msec}, S E=$ 18) as compared with the divided attention (mean $=$ $717 \mathrm{msec}, S E=23$ ) stream as expected. A marginally significant Group effect was also present, $F(1,26)=$ $3.58, p=.07, \eta^{2}=.12$, indicating shorter RTs in AVGPs $($ mean $=654 \mathrm{msec}, S E=29)$ compared with NAVGPs (mean $=730 \mathrm{msec}, S E=29)$. Most importantly, a significant interaction between the factors Attention and Group was observed, $F(1,26)=4.89, p=.036, \eta^{2}=$ .16. Follow-up analyses of this interaction confirmed shorter RTs in the focused attention condition in the AVGPs than NAVGPs, $t(26)=2.77, p=.01$ (AVGPs mean focused $=617 \mathrm{msec}, S E=25$; NAVGPs mean focused $=716 \mathrm{msec}, S E=25$ ), and no group difference in the divided attention condition, $t(26)=1.2, p=.26$ (AVGPs mean divided $=690 \mathrm{msec}, S E=33$; NAVGPs mean divided $=744 \mathrm{msec}, S E=33$; Figure 1C).

\section{EEG Results}

\section{Posterior ERP Components}

C1 (65-105 msec). The initial C1 component was maximally negative over the midline parieto-occipital scalp. The ANOVA run with the factors Group (NAVGPs, AVGPs) and Attention (focused, divided, unattended) confirmed that the amplitude of the $\mathrm{C} 1$ component was not modulated by Attention $(p=.87)$; importantly it also did not differ as a function of Group $(p=.69)$ nor was there a Group by Attention interaction $(p=.46)$.

P1 (115-160 msec). The scalp distribution of the P1 was maximally positive over posterior parietal and occipital scalp sites contralateral to the location of the stimuli. The ANOVA with Group (AVGPs, NAVGPs), Attention (focused, divided, unattended), and Hemisphere (contralateral, ipsilateral to standard Gabor stimulus) as factors revealed, as expected, a highly significant modulation by the factor Attention, $F(2,52)=15.28, p<.001, \eta^{2}=.33$. A smaller P1 amplitude to stimuli in response to the unattended stream (mean $=0.61, S E=0.15)$ was observed as compared with the focused-attended stream (mean = 1.39, $S E=0.2, p<.001)$ and divided-attended streams 
(mean $=1.17, S E=0.19, p=.002$ ) with no significant difference between the focused and divided attention streams $(p=.84)$. A significant Attention by Hemisphere interaction effect was noted, $F(2,52)=10.34, p<.001$, $\eta^{2}=.29$, due to different degrees of P1 lateralization under the different attention conditions. Most relevant given our aims, however, neither the main effect of Group nor any of the interactions with Group were significant (Figure 2; all $p s>.51$ ).

Posterior N1 (170-215 $\mathrm{msec})$. The posterior N1 was found to be maximally negative over posterior parietal and occipital scalp sites contralateral to the position of the stimuli. The ANOVA with Group (AVGPs, NAVGPs), Attention (focused, divided, unattended), and Hemisphere (contralateral, ipsilateral to standard Gabor stimulus) as factors revealed that the posterior N1 was significantly modulated by Attention, $F(2,52)=12.73$, $p<.001, \eta^{2}=.33$, as expected. A more pronounced negativity was observed to the focused (mean = $-1.03, S E=0.23$ ) compared with the divided attention
$($ mean $=-0.65, S E=0.17)$ and the unattended streams (mean $=-0.21, S E=0.16$, all $p s<.017)$. The ERPs to the divided attention streams also showed a more pronounced negativity compared with ERPs to the unattended stream $(p=.009)$. A significant Attention by Hemisphere interaction was also observed, $F(2,52)=$ $14.33, p<.001, \eta^{2}=.36$, due to differences in N1 lateralization across the different attention conditions. Again, neither the main effect of Group nor any other interactions with the Group factor were significant (Figure 2; all $p s>.8)$.

\section{Anterior ERP Components}

Anterior N1 (125-175 $\mathrm{msec})$. The anterior N1 was found to be maximally negative over frontal central scalp sites contralateral to the location of the stimuli. The ANOVA indicated a significant main effect of Attention, $F(2,52)=6.19, p=.005, \eta^{2}=.19$. Post hoc tests revealed an enhanced amplitude of the anterior N1 in the focused-attended stream (mean $=-0.94, S E=0.17$ ) as

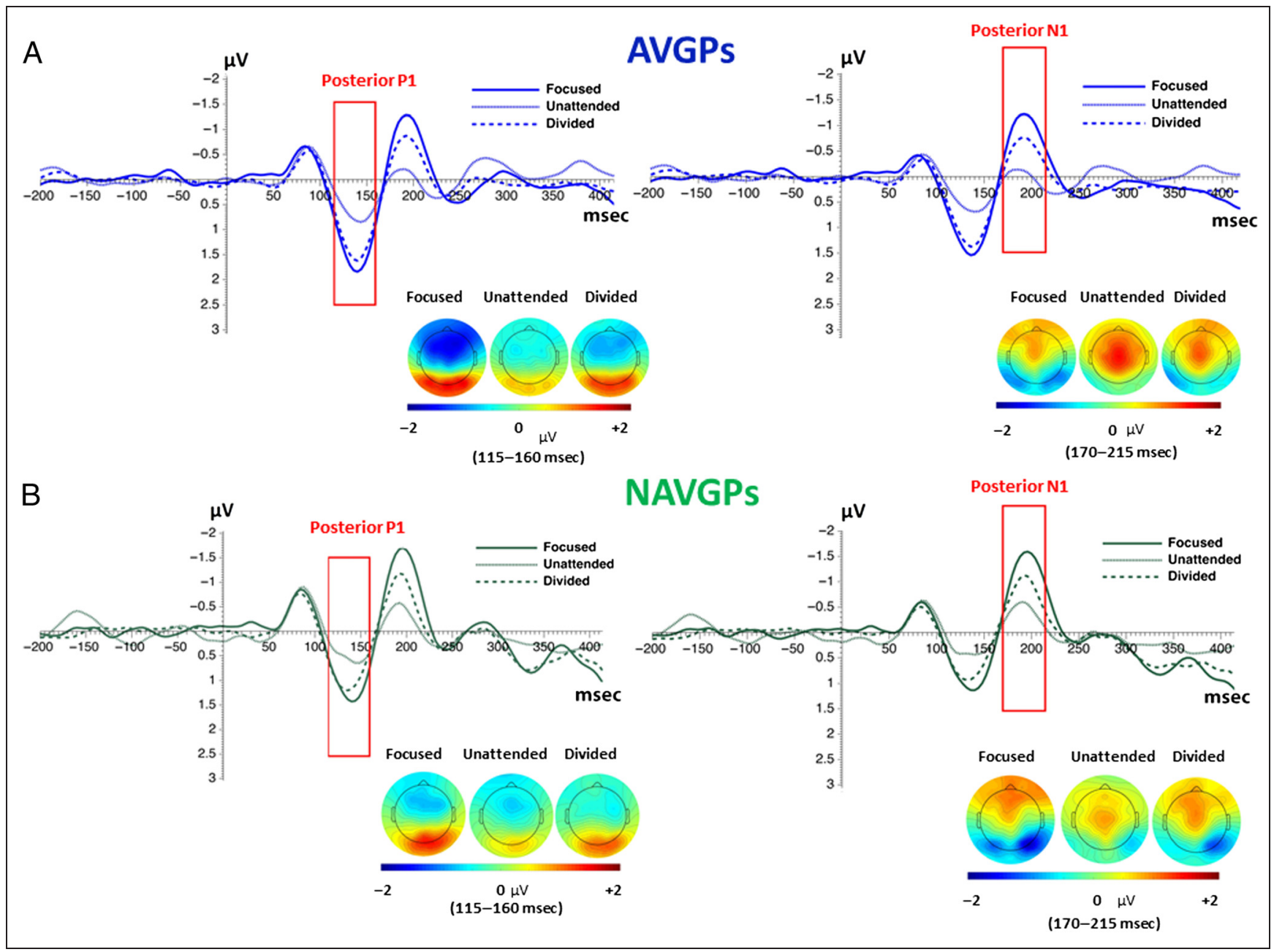

Figure 2. ERPs time-locked to the onset of the standard Gabors in the time range of the posterior P1 (115-160 msec; left side) and the posterior N1 (170-215 msec; right side) in three attention conditions (focused [solid line], unattended [solid thin line], and divided [dashed line]) for (A) AVGPs (blue) and (B) NAVGPs (green) collapsed across ipsilateral and contralateral electrode sites: P1: O1/O2, PO7/PO8, I3/I4; posterior N1: $\mathrm{P} 8 / \mathrm{P} 7, \mathrm{PO} 8 / \mathrm{PO} 8, \mathrm{I} 4 / \mathrm{I} 3$. Topographies are shown for the three attention conditions and for each group separately. 
compared with both the unattended (mean $=0.37, S E=$ $0.13, p=.002$ ) and divided attention (mean $=-0.51$, $S E=0.14, p=.029)$ streams. However, mean amplitudes of the anterior N1 did not differ between unattended and divided streams $(p=.37)$. There was also a significant main effect of Hemisphere, $F(1,26)=40.7, p<.001$, $\eta^{2}=.61$, due to higher mean amplitudes contralaterally (mean $=-0.87, S E=0.11)$ compared with ipsilaterally (mean $=-0.034, S E=0.12$ ) with respect to stimulus position; there was also a significant interaction between Attention and Hemisphere, $F(2,52)=3.8, p=.029, \eta^{2}=$ .13 , as the amplitude differences between the hemispheres differed among the three attention conditions.

Most importantly, there was a significant Attention by Group interaction, $F(2,52)=3.6, p=.035, \eta^{2}=.121$. Follow-up ANOVAs showed that there was a significant effect of Attention for AVGPs, $F(2,26)=9.75, p=$ $.001, \eta^{2}=.43$, as the anterior $\mathrm{N} 1$ amplitude in response to the focused-attended stream (mean $=-1.31, S E=$ $0.24)$ was larger compared with the unattended (mean $=$

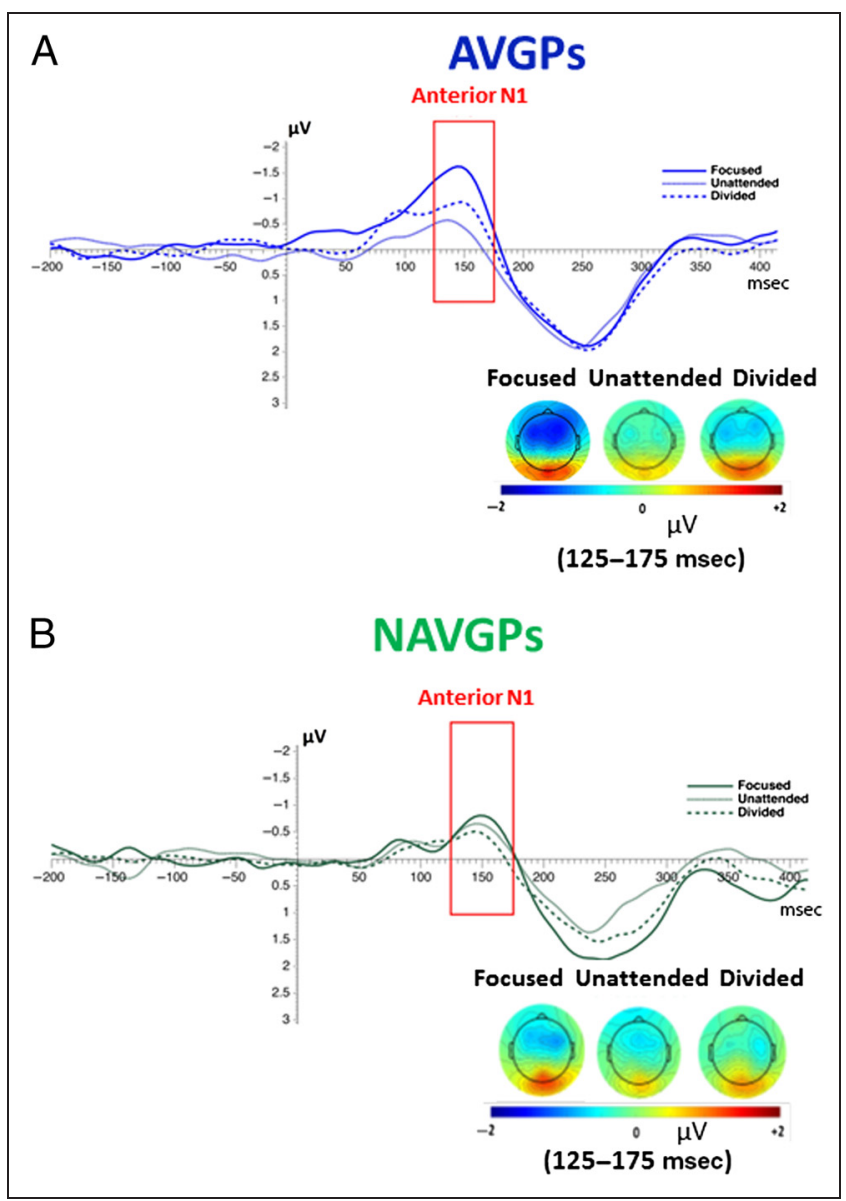

Figure 3. ERPs time-locked to the onset of the standard Gabors patches in the time range of the anterior N1 (125-175 msec) in three attention conditions (focused [solid line], unattended [solid thin line], and divided [dashed line]) for (A) AVGPs (blue) and (B) NAVGPs (green) collapsed across ipsilateral and contralateral electrode sites: AF3/AF4, F3/F4, F7/F8, FC5/FC6. Topographies are shown for the three attention conditions and for each group separately.

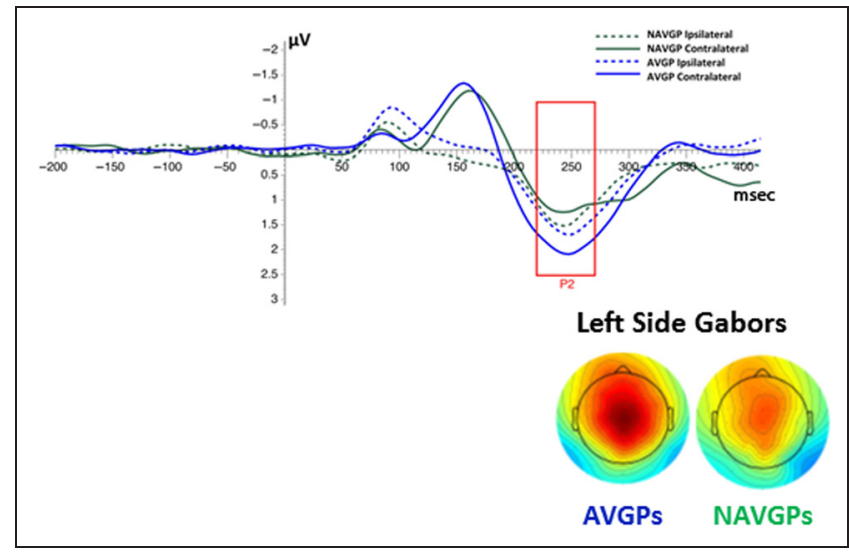

Figure 4. ERPs time-locked to the onset of the standard Gabors in the time range of the P2 (220-270 msec) in AVGPs (blue lines) and NAVGPs (green lines) separately for electrodes ipsilateral (dashed lines) or contralateral (solid lines) to the side of the Gabor patches (blue AVGPs, green NAVGPs). Topography maps are shown for the conditions in which a standard Gabor was presented on the left side for the groups separately.

$-.3 S E=0.18, p<.001)$ and divided attention (mean $=$ $-0.7 S E=0.2(p=.017)$ streams (Figure 3). No such attentional modulation was observed for NAVGPs, $F(2$, $26)=.51, p=.61$. Accordingly, for the focused stream, the anterior N1 was greater in amplitude in AVGPs compared with NAVGPs, $F(1,26)=4.84, p=.037, \eta^{2}=.16$. There were no other significant interaction effects ( $p s>$ .1 ; see Figure 3). One might have expected the anterior $\mathrm{N} 1$ amplitude, especially under focused attention, to be correlated with behavioral performance, yet this was not the case.

P2 (220-270 msec). The P2 component showed a maximum positive amplitude over the central scalp. The P2 was not modulated by Attention, $F(2,52)=.9, p=.41$, nor were the main effects of Hemisphere, $F(1,26)=$ $1.03, p=.32$, or Group, $F(1,26)=1.7, p=.2$, significant. Moreover, there was no interaction between the factors Attention and Group, $F(2,52)=.5, p=.61$. However, there was a significant Group by Hemisphere interaction, $F(1,26)=5.52, p=.027, \eta^{2}=.18$, indicating a significant Hemisphere effect for AVGPs, $F(1,13)=6.55, p=$ $.024, \eta^{2}=.12$, and no such effect for NAVGPs, $F(1,13)=$ $.79, p=.39$ (see Figure 4). AVGPs showed a more pronounced positivity at electrode sites contralateral to the standard Gabor stimuli (mean $=2.00, S E=0.29$ ) as compared with ipsilateral sites $($ mean $=1.56, S E=0.26)$. This was not the case in NAVGPs, where the two hemispheres did not differ significantly in P2 amplitude (mean contralateral $=1.21, S E=0.29$, mean ipsilateral $=1.38, S E=$ $0.26)$. Related to these laterality effects, there was a marginally significant difference between the groups at the electrode sites contralateral to the standard Gabors (Group effect: $F(1,26)=3.57, p=.07$ ) but not at the ipsilateral sites $(p>3)$. There were no other significant interactions $(p s>.1)$. 
Target-locked P3. Independent samples $t$ tests were calculated between groups on the mean amplitude of P3 time-locked to the target Gabors over the interval 500-700 msec posttarget onset where its amplitude was maximal. There was no significant difference in mean amplitudes between AVGPs (mean $=12.06, S E=$ $1.31)$ and NAVGPs $($ mean $=14.52, S E=2.04), t(26)=$ $1.01, p=.32$.

Response-locked P3. Independent samples $t$ tests were calculated between groups on mean amplitudes of the response-locked $\mathrm{P} 3$ over the interval -50 to $250 \mathrm{msec}$ with respect to the motor response. There was no significant difference between AVGPs (mean $=8.36, S E=$ $1.61)$ and NAVGPs (mean $=7.05, S E=1.83), t(26)=$ $-.54, p=.6$. The mean amplitudes of the target-locked P3 correlated marginally across all participants with $d^{\prime}(r=$ $.333, p=.083)$ and significantly with RTs $(r=-.431, p=$ .022). Thus, as expected, the higher the amplitude of the target-locked $\mathrm{P} 3$, the faster and more accurate participants were at detecting the Gabor targets among the standards.

\section{DISCUSSION}

This study used visual ERPs to contrast neural activity during an attention-demanding perceptual task in AVGPs and NAVGPs. Following a visual cue, rapid sequences of flashed Gabor patches were presented in the right and the left visual fields while participants either attended selectively to one of the sequences or divided their attention to both sequences with the task of detecting occasional deviant Gabor targets. AVGPs showed behavioral trends in line with their expected heightened perceptual and attentional capacities as was evident in their faster (and equally accurate) target detection responses compared with NAVGPs. Unlike what was expected, however, no group differences were observed in any of the striate or early extrastriate occipital ERP components, in particular the P1 and posterior N1. The most prominent difference between the groups was in the early anterior N1 component associated with parietal lobe functions, with greater amplitudes in the AVGPs compared with the NAVGPs during focused attention. The centrally distributed P2 component was also larger in amplitude in the AVGP group at electrode sites contralateral to the side of the eliciting stimulus.

Behaviorally, AVGPs tended to be faster in responding to targets than NAVGPs, and this effect was clearly significant in response to targets in the focused attention stream. Importantly, AVGPs exhibited similar target detection sensitivity $\left(d^{\prime}\right)$ compared with NAVGPs, indicating that although they tended to respond faster, they did not compromise on accuracy of target detections (see also Dye et al., 2009). This pattern of behavioral results is in line with previous studies demonstrating improved performance in AVGPs in visual attention-demanding tasks (see Green \& Bavelier, 2015). In this study, this perfor- mance difference was more marked under focused than divided attention. There are reports, however, of an AVGP advantage also under divided attention (West et al., 2008; Green \& Bavelier, 2006b). Most previous divided attention tasks presented target and distractor stimuli concurrently rather than sequentially. Although we cannot rule out the possibility that the lack of concurrent competing stimuli is at the source of the null group effect reported here for the divided attention condition, several findings in the literature render this explanation unlikely. In particular, enhanced performance in AVGPs as compared with NAVGPs has been found using isolated stimuli presented in rapid succession in paradigms as varied as the Attentional Blink (Oei \& Patterson, 2013, 2015; Dye \& Bavelier, 2010; Boot, Kramer, Simons, Fabiani, \& Gratton, 2008; Cohen et al., 2007; Green \& Bavelier, 2003), visual backward masking (Pohl et al., 2014; Li et al., 2010), temporal order judgment (Donohue, Woldorff, \& Mitroff, 2010), and the continuous performance task (Cardoso-Leite et al., 2016) to cite a few. Although these were not divided attention paradigms, it is clear that group differences are not restricted to conditions where targets and distractors are presented simultaneously. It may be that the divided attention task in the present experiment was especially difficult given the fast rate of Gabor presentations at variable times and locations. Indeed, group differences can be easily obscured when tasks are either too easy or too hard, as these extreme conditions push the contrasted groups either near a ceiling or a floor effect.

In agreement with several previous studies, the P1 (115-160 msec) and posterior N1 (170-215 msec) components, which have both been localized to neural generators in extrastriate visual cortex of the occipital lobe (Di Russo et al., 2003, 2012), were strongly enhanced by attention. As expected, larger P1 and posterior N1 components were elicited with increasing allocations of attention to the stimulus location. Accordingly, the amplitudes of these components under the focused attention condition were greater than those elicited in the unattended or divided attention conditions (Proverbio \& Mangun, 1994; Mangun \& Hillyard, 1990; reviewed in Hopfinger et al., 2004; Luck \& Hillyard, 2000). Importantly, neither of these components differed between AVGPs and NAVGPs, providing little support for group differences in early stimulus selection processes in the striate or extrastriate visual pathways as a result of action video game play. Thus, although improvements in visual attention and perception have been documented in AVGPs that conceivably could have resulted from changes in attentional gating of visual information in low-level visual areas, this study does not provide any support for such neuroplastic changes at the level of striate or extrastriate cortices.

In contrast, the anterior N1 component (125-175 msec) did show a more pronounced negativity for AVGPs than for NAVGPs, especially in response to standard Gabors 
in the focus of attention. In line with previous reports, the anterior N1 displayed the same pattern of enhancement with attention as the P1 and the posterior N1-that is, a greater amplitude in response to the focused stream compared with the unattended and divided attention streams. This group difference in anterior N1 modulation for the focused stream mirrors the faster RTs in AVGPs compared with NAVGPs found under focused attention. The dipole source of the anterior N1 has been modeled to lie in the vicinity of the intraparietal sulcus (Di Russo et al., 2003, 2012), a key region involved in the voluntary orienting of spatial attention and maintaining the attentional focus upon relevant locations (Corbetta, Kincade, Ollinger, McAvoy, \& Shulman, 2000; Hopfinger, Buonocore, \& Mangun, 2000; Kastner, Pinsk, De Weerd, Desimone, \& Ungerleider, 1999). Thus, the enhanced anterior N1 modulation in AVGPs may reflect their superiority at efficiently focusing their attentional spotlight on relevant information, that is, exerting more effective attentional control compared with NAVGPs. This result is in line with reports that AVGPs have a greater ability to suppress task-irrelevant stimuli, a process also attributed to parietal mechanisms (Krishnan et al., 2013; Mishra et al., 2011). Here, however, the group difference was most marked as an enhancement of the information in the focus of attention, rather than a greater suppression of unattended information. It thus remains unclear whether the superior attentional control attributed to AVGPs may be mostly mediated via better distractor suppression, better attentional enhancement, or some combination of the two depending on tasks characteristics.

In contrast with these early effects, the P2 (220$270 \mathrm{msec}$ ), a component that may have multiple generators around the parieto-occipital sulcus (Di Russo et al., 2003 , 2012), was not modulated by attention, but differed in its pattern of hemispheric lateralization between the two groups. In particular, the P2 was marginally enhanced for AVGPs compared with NAVGPs, but only for ERPs recorded over the hemisphere contralateral to the standard Gabor patches. Previous studies have suggested that this component is enhanced by overall task demands (Fritzsche et al., 2011; Potts et al., 2004). The P2 effect observed here was rather subtle, indicating an enhanced response in AVGPs over contralateral scalp electrodes to standard Gabors, independent of their attentional status. This group difference may reflect the enhanced ability of AVGPs for target matching; yet, caution is needed in interpreting this group difference, as the amplitude of the P2 can be altered by many different aspects of visual processing, and its functional interpretation remains uncertain. Interestingly, the training study conducted by Wu et al. (2012) also documented an increased P2 amplitude after action video game play, at least in participants for whom the action video game intervention was the most effective as assessed by an attention demanding visual field task. No such association between P2 change and behavior was found here.
In contrast to previous studies (Wu et al., 2012; Mishra et al., 2011), we did not observe enhanced ERP amplitudes in AVGPs compared with NAVGPs in the time range of the stimulus-locked or response-locked P3 components. The source of this difference across studies remains unclear, although we note that group differences in P3 in some previous studies were relatively weak (e.g., one-tailed tests used in Mishra et al., 2011). Possibly the lack of a $\mathrm{P} 3$ difference between groups in this study has to do with the absence of any group difference in target detection sensitivity, because the P3 amplitude is known to be strongly determined by target detection sensitivity and confidence (reviewed in Hillyard \& Picton, 1987; Hillyard \& Kutas, 1983).

In light of the lack of expected group differences in the $\mathrm{P} 1$ and posterior $\mathrm{N} 1$ components, it is worth considering this null finding in the context of the larger literature. First, as far as we know, only one other neuroimaging study, that of Wu et al. (2012), has addressed the issue of low- and mid-level processing changes after action video game play. Wu et al. (2012) reported no group differences in either the P1 or posterior N1 component elicited during a visual search task following a 10-hr intervention that contrasted an action video game trained group to a control trained group. Although this result is certainly in line with our findings, this study significantly extends the findings of Wu et al. (2012) in several respects. First, it is well known that plastic changes are more modest in intervention studies than in crosssectional studies that compare groups with differing gaming experience (e.g., Bediou et al., 2017). Thus, $10 \mathrm{hr}$ of action game play may not have been sufficient to alter top-down attentional control processes that modulate low- and mid-level visual processing pathways. In contrast, our study selected and contrasted the same extreme subpopulations as those previously documented in the literature to exhibit the greatest perceptual and attentional group differences. Accordingly, the AVGPs in this study had been playing action video games for an average of $9 \mathrm{hr}$ per week during a period of at least 2 years, whereas the NAVGPs had been playing at most $3 \mathrm{hr}$ per week of all games combined and less than $1 \mathrm{hr}$ of action video game play weekly for at least 2 years. Second, the conclusions derived from the Wu et al. (2012) study are further weakened by the absence of any significant differences between their action-trained and their control trained group. Rather, within the action-trained groups, only the subgroup of individuals who showed greater behavioral enhancements than the members of the control trained group showed a marginally significant greater positivity in P2 and a larger stimulus-evoked P3 than the controls. When considering the entire action-trained versus the control trained group, none of the ERP components differed significantly, hindering any interpretation of the observed lack of group differences in the P1 and posterior N1 components. The present study is thus the first to document an 
absence of group differences in low- and mid-level processing stages, as indexed by the P1 and posterior N1 components, in the context of significant group differences in other ERP components.

We recognize that our sample size of 14 participants per group was relatively modest, as power analyses indicate the need for 26 participants per group for a Cohen's $d$ effect size of 0.7 (average between Hedge's $g$ effect sizes of .62 and .77 for, respectively, top-down attention and perception cross-section studies from the Bediou et al., 2017, meta-analysis), with a one-tailed alpha level of .05 and a power of .8 . Yet, it should be noted that the present analyses were able to detect group differences in the anterior N1 and P2 components, indicating that the paradigm was sensitive enough to detect neuroplastic changes in parietally generated ERP activity. Although we recognize that a larger sample size would have been preferable, the lack of group differences in $\mathrm{P} 1$ and posterior N1 remains surprising and thus informative in the context of the accumulated body of research in this area.

In conclusion, this study investigated the neural bases of the superior perceptual and attentional capacities of AVGPs using an RSVP task in which participants had to either focus their attention on one visual stream while ignoring a distractor stream or to divide their attention between the two streams. Both groups had similar sensitivity when discriminating targets from standard stimuli, but AVGPs were faster in responding to targets than NAVGPs. Electrophysiological data suggest a more effective control of spatial attention for the AVGPs, as indexed by an increased amplitude of the parietally generated anterior N1 component of the ERP when attention was focused on the visual stream in one hemifield. Importantly, there were no effects of action video game play on the early occipital ERP components (P1 and posterior N1), which are known to systematically increase in amplitude with increasing allocation of attention to a stimulus location. These results suggest that the superior perceptual and attentional performance in AVGPs may not be mediated through a difference in low-level sensory gain control or better early discrimination of the relevant stimulus properties, as indicated by the differential roles ascribed to the P1 and posterior N1, respectively (Itthipuripat, Cha, Byers, \& Serences, 2017; Handy \& Mangun, 2000; Vogel \& Luck, 2000; Luck et al., 1990, 1994). Rather, the present finding of an enhanced anterior N1 component in AVGPs supports the emerging view that extensive experience with action video games is linked to a superior ability to flexibly allocate the attentional spotlight as task demand varies. A more effective control over directing the spotlight of attention to relevant locations may allow AVGPs to more optimally sample and integrate information in the service of decision-making, a needed skill when facing the rich and attentionally demanding environment of action video games.

\section{Acknowledgments}

We are grateful to K. Brooks for editorial contributions to the manuscript. We also thank B. Bediou and T. Schenk. This work was supported by NEI EY020976, the Swiss National Fund 100014_140676, the German Research Foundation (DFG, FO 786), and the U.S. Office of Naval Research (N00014-07-1-0937).

Reprint requests should be sent to Julia Föcker, Faculty of Psychology and Educational Sciences, Ludwig-Maximilians-University of Munich, Leopoldstraße 13, Room 3117, 80802 München, Germany, or via e-mail: Julia.Foecker@psy.lmu.de.

\section{REFERENCES}

Ahissar, M., \& Hochstein, S. (2004). The reverse hierarchy theory of visual perceptual learning. Trends in Cognitive Sciences, 8, 457-464.

Appelbaum, L. G., Cain, M. S., Darling, E. F., \& Mitroff, S. R. (2013). Action video game playing is associated with improved visual sensitivity, but not alterations in visual sensory memory. Attention, Perception, E Psychophysics, 75, 1161-1167.

Baumgartner, H. M., Graulty, C. J., Hillyard, S. A., \& Pitts, M. A. (2017a). Does spatial attention modulate the earliest component of the visual evoked potential? Cognitive Neuroscience. doi:10.1080/17588928.2017.1333490.

Baumgartner, H. M., Graulty, C. J., Hillyard, S. A., \& Pitts, M. A. (2017b). Does spatial attention modulate the C1 component? The jury continues to deliberate. Cognitive Neuroscience. doi:10.1080/17588928.2017.1386169.

Bavelier, D., Achtman, R. L., Mani, M., \& Föcker, J. (2012a). Neural bases of selective attention in action video game players. Vision Research, 61, 132-143.

Bavelier, D., \& Föcker, J. (2015). Video games in the spotlight: The case of attentional control. In J. M. Fawcett, E. F. Risko, \& A. Kingstone (Eds.), The handbook of attention. Cambridge, MA: MIT Press.

Bavelier, D., Green, C. S., Pouget, A., \& Schrater, P. (2012b). Brain plasticity through the life span: Learning to learn and action video games. Annual Review of Neuroscience, 35, 391-416.

Bediou, B., Adams, D. M., Mayer, R. E., Tipton, E., Green, C. S., \& Bavelier, D. (2017). Meta-analysis of action video game impact on perceptual, attentional, and cognitive skills. Psychological Bulletin.

Bejjanki, V. R., Zhang, R., Li, R., Pouget, A., Green, C. S., Lu, Z.-L., et al. (2014). Action video game play facilitates the development of better perceptual templates. Proceedings of the National Academy of Sciences, U.S.A., 111, 16961-16966.

Bendixen, A., \& Andersen, S. K. (2013). Measuring target detection performance in paradigms with high event rates. Clinical Neurophysiology, 124, 928-940.

Blacker, K. J., Curby, K. M., Klobusicky, E., \& Chein, J. M. (2014). Effects of action video game training on visual working memory. Journal of Experimental Psychology: Human Perception and Performance, 40, 1992-2004.

Boot, W. R., Kramer, A. F., Simons, D. J., Fabiani, M., \& Gratton, G. (2008). The effects of video game playing on attention, memory, and executive control. Acta Psychologica, 129, 387-398.

Cain, M. S., Landau, A. N., \& Shimamura, A. P. (2012). Action video game experience reduces the cost of switching tasks. Attention, Perception, \& Psychophysics, 74, 641-647.

Cain, M. S., Prinzmetal, W., Shimamura, A. P., \& Landau, A. N. (2014). Improved control of exogenous attention in action video game players. Frontiers in Psychology, 5, 69. 
Cardoso-Leite, P., Kludt, R., Vignola, G., Ma, W. J., Green, C. S., \& Bavelier, D. (2016). Technology consumption and cognitive control: Contrasting action video game experience with media multitasking. Attention, Perception, $\mathcal{E}$ Psychophysics, 78, 218-241.

Castel, A. D., Pratt, J., \& Drummond, E. (2005). The effects of action video game experience on the time course of inhibition of return and the efficiency of visual search. Acta Psychologica, 119, 217-230.

Chisholm, J. D., Hickey, C., Theeuwes, J., \& Kingstone, A. (2010). Reduced attentional capture in action video game players. Attention, Perception, \& Psychophysics, 72, 667-671.

Chisholm, J. D., \& Kingstone, A. (2012). Improved top-down control reduces oculomotor capture: The case of action video game players. Attention, Perception, \& Psychophysics, 74, 257-262.

Chisholm, J. D., \& Kingstone, A. (2015). Action video games and improved attentional control: Disentangling selection-and response-based processes. Psychonomic Bulletin \& Review, 22, 1430-1436.

Clark, K., Fleck, M. S., \& Mitroff, S. R. (2011). Enhanced change detection performance reveals improved strategy use in avid action video game players. Acta Psychologica, 136, 67-72.

Clark, V. P., \& Hillyard, S. A. (1996). Spatial selective attention affects early extrastriate but not striate components of the visual evoked potential. Journal of Cognitive Neuroscience, 8, 387-402.

Cohen, J. E., Green, C. S., \& Bavelier, D. (2007). Training visual attention with video games: Not all games are created equal. In H. O'Neil \& R. Perez (Eds.), Computer games and adult learning (pp. 205-227). Amsterdam: Elsevier.

Corbetta, M., Kincade, J. M., Ollinger, J. M., McAvoy, M. P., \& Shulman, G. L. (2000). Voluntary orienting is dissociated from target detection in human posterior parietal cortex. Nature Neuroscience, 3, 292-297.

Corbetta, M., Patel, G., \& Shulman, G. L. (2008). The reorienting system of the human brain: From environment to theory of mind. Neuron, 58, 306-324.

Crist, R. E., Li, W., \& Gilbert, C. D. (2001). Learning to see: Experience and attention in primary visual cortex. Nature Neuroscience, 4, 519-525.

Delorme, A., \& Makeig, S. (2004). EEGLAB: An open source toolbox for analysis of single-trial EEG dynamics including independent component analysis. Journal of Neuroscience Methods, 134, 9-21.

Ding, Y., Martínez, A., Qu, Z., \& Hillyard, S. A. (2014). Earliest stages of visual cortical processing are not modified by attentional load. Human Brain Mapping, 35, 3008-3024.

Di Russo, F., Martínez, A., \& Hillyard, S. A. (2003). Source analysis of event-related cortical activity during visuo-spatial attention. Cerebral Cortex, 13, 486-499.

Di Russo, F., Martínez, A., Sereno, M. I., Pitzalis, S., \& Hillyard, S. A. (2002). Cortical sources of the early components of the visual evoked potential. Human Brain Mapping, 15, 95-111.

Di Russo, F., Stella, A., Spitoni, G., Strappini, F., Sdoia, S., Galati, G., et al. (2012). Spatio-temporal brain mapping of spatial attention effects on pattern-reversal ERPs. Human Brain Mapping, 33, 1334-1351.

Donohue, S. E., James, B., Eslick, A. N., \& Mitroff, S. R. (2012). Cognitive pitfall! Videogame players are not immune to dualtask costs. Attention, Perception, \& Psychophysics, 74, 803-809.

Donohue, S. E., Woldorff, M. G., \& Mitroff, S. R. (2010). Video game players show more precise multisensory temporal processing abilities. Attention, Perception, E Psychophysics, 72, 1120-1129.

Dye, M. W., \& Bavelier, D. (2010). Differential development of visual attention skills in school-aged children. Vision Research, 50, 452-459.
Dye, M. W., Green, C. S., \& Bavelier, D. (2009). The development of attention skills in action video game players. Neuropsychologia, 47, 1780-1789.

Föcker, J., Cole, D., Beer, A., \& Bavelier, D. (under review). Neural bases of enhanced attentional: Lessons from action video game players.

Fritzsche, A. S., Stahl, J., \& Gibbons, H. (2011). An ERP study of target competition: Individual differences in functional impulsive behavior. International Journal of Psychophysiology, 81, 12-21.

Gilbert, C. D., \& Li, W. (2013). Top-down influences on visual processing. Nature Reviews Neuroscience, 14, 350-363.

Green, C. S., \& Bavelier, D. (2003). Action video game modifies visual selective attention. Nature, 423, 534-537.

Green, C. S., \& Bavelier, D. (2006a). Effect of action video games on the spatial distribution of visuospatial attention. Journal of Experimental Psychology: Human Perception and Performance, 32, 1465-1478.

Green, C. S., \& Bavelier, D. (2006b). Enumeration versus multiple object tracking: The case of action video game players. Cognition, 101, 217-245

Green, C. S., \& Bavelier, D. (2007). Action-video-game experience alters the spatial resolution of vision. Psychological Science, 18, 88-94.

Green, C. S., \& Bavelier, D. (2012). Learning, attentional control, and action video games. Current Biology, 22, R197-R206.

Green, C. S., \& Bavelier, D. (2015). Action video game training for cognitive enhancement. Current Opinion in Behavioral Sciences, 4, 103-108.

Green, C. S., Pouget, A., \& Bavelier, D. (2010). Improved probabilistic inference as a general learning mechanism with action video games. Current Biology, 20, 1573-1579.

Green, C. S., Sugarman, M. A., Medford, K., Klobusicky, E., \& Bavelier, D. (2012). The effect of action video game experience on task-switching. Computers in Human Behavior, 28, 984-994.

Greenfield, P. M., DeWinstanley, P., Kilpatrick, H., \& Kaye, D. (1994). Action video games and informal education: Effects on strategies for dividing visual attention. Journal of Applied Developmental Psychology, 15, 105-123.

Handy, T. C., \& Mangun, G. R. (2000). Attention and spatial selection: Electrophysiological evidence for modulation by perceptual load. Perception \& Psychophysics, 62, 175-186.

Harris, H., Gliksberg, M., \& Sagi, D. (2012). Generalized perceptual learning in the absence of sensory adaptation. Current Biology, 22, 1813-1817.

Hillyard, S. A., \& Anllo-Vento, L. (1998). Event-related brain potentials in the study of visual selective attention. Proceedings of the National Academy of Sciences, U.S.A. 95, 781-787.

Hillyard, S. A., \& Kutas, M. (1983). Electrophysiology of cognitive processing. Annual Review of Psychology, 34, 33-61.

Hillyard, S. A., \& Picton, T. W. (1987). Electrophysiology of cognition. In F. Plum (Ed.), Handbook of physiology: Higher functions of the nervous system, section 1: The nervous system: Volume V, Higher functions of the brain, Part 2 (pp. 519-584). Bethesda, MD: American Physiological Society.

Hopfinger, J. B., Buonocore, M. H., \& Mangun, G. R. (2000). The neural mechanisms of top-down attentional control. Nature Neuroscience, 3, 284-291.

Hopfinger, J. B., Luck, S. J., \& Hillyard, S. A. (2004). Selective attention: Electrophysiological and neuromagnetic studies. In M. S. Gazzaniga (Ed.), The cognitive neurosciences (pp. 561-574). Cambridge, MA: MIT Press.

Hubert-Wallander, B., Green, C. S., Sugarman, M., \& Bavelier, D. (2011). Changes in search rate but not in the dynamics of 
exogenous attention in action videogame players. Attention, Perception, E Psychophysics, 73, 2399-2412.

Itthipuripat, S., Cha, K., Byers, A., \& Serences, J. T. (2017). Two different mechanisms support selective attention at different phases of training. PLoS Biology, 15, e2001724.

James, A. C., Ruseckaite, R., \& Maddess, T. (2005). Effect of temporal sparseness and dichoptic presentation on multifocal visual evoked potentials. Visual Neuroscience, 22, 45-54.

Kahnt, T., Grueschow, M., Speck, O., \& Haynes, J. D. (2011). Perceptual learning and decision-making in human medial frontal cortex. Neuron, 70, 549-559.

Kastner, S., Pinsk, M. A., De Weerd, P., Desimone, R., \& Ungerleider, L. G. (1999). Increased activity in human visual cortex during directed attention in the absence of visual stimulation. Neuron, 22, 751-761.

Krishnan, L., Kang, A., Sperling, G., \& Srinivasan, R. (2013). Neural strategies for selective attention distinguish fast-action video game players. Brain Topography, 26, 83-97.

Law, C.-T., \& Gold, J. I. (2008). Neural correlates of perceptual learning in a sensory-motor, but not a sensory, cortical area. Nature Neuroscience, 11, 505-513.

Li, R., Polat, U., Makous, W., \& Bavelier, D. (2009). Enhancing the contrast sensitivity function through action video game training. Nature Neuroscience, 12, 549-551.

Li, R., Polat, U., Scalzo, F., \& Bavelier, D. (2010). Reducing backward masking through action game training. Journal of Vision, 10, 33.

Lopez-Calderon, J., \& Luck, S. J. (2014). ERPLAB: An opensource toolbox for the analysis of event-related potentials. Frontiers in Human Neuroscience, 8, 213.

Luck, S. J., Chelazzi, L., Hillyard, S. A., \& Desimone, R. (1997). Neural mechanisms of spatial selective attention in areas V1, $\mathrm{V} 2$, and $\mathrm{V} 4$ of macaque visual cortex. Journal of Neurophysiology, 77, 24-42.

Luck, S. J., \& Gaspelin, N. (2017). How to get statistically significant effects in any ERP experiment (and why you shouldn't). Psychophysiology, 54, 146-157.

Luck, S. J., Heinze, H. J., Mangun, G. R., \& Hillyard, S. A. (1990). Visual event-related potentials index focused attention within bilateral stimulus arrays. II. Functional dissociation of P1 and N1 components. Electroencephalography and Clinical Neurophysiology, 75, 528-542.

Luck, S. J., \& Hillyard, S. A. (2000). The operation of selective attention at multiple stages of processing: Evidence from human and monkey electrophysiology. In M. S. Gazzaniga (Ed.), The new cognitive neurosciences (2nd Ed., pp. 687-700). Cambridge, MA: MIT Press.

Luck, S. J., \& Hillyard, S. A. (2014). Electrophysiology of visual attention in humans. Chapter 18. In M. S. Gazzaniga \& G. R. Mangun (Eds.), The cognitive neurosciences $V$ (pp. 179-187) Cambridge, MA: MIT Press.

Luck, S. J., Hillyard, S. A., Mouloua, M., Woldorff, M. G., Clark, V. P., \& Hawkins, H. L. (1994). Effects of spatial cuing on luminance detectability: Psychophysical and electrophysiological evidence for early selection. Journal of Experimental Psychology: Human Perception and Performance, 20, 887-904.

Macmillan, N. A., \& Creelman, C. D. (1991). Detection theory: A user's guide. New York: Cambridge University Press.

Mangun, G. R., \& Hillyard, S. A. (1987). The spatial allocation of visual attention as indexed by event-related brain potentials Human Factors, 29, 195-211.

Mangun, G. R., \& Hillyard, S. A. (1990). Allocation of visual attention to spatial locations: Tradeoff functions for eventrelated brain potentials and detection performance. Perception \& Psychophysics, 47, 532-550.

Martínez, A., Di Russo, F., Anllo-Vento, L., Sereno, M. I., Buxton, R. B., \& Hillyard, S. A. (2001). Putting spatial attention on the map: Timing and localization of stimulus selection processes in striate and extrastriate visual areas. Vision Research, 41, $1437-1457$.

Mishra, J., Zinni, M., Bavelier, D. \& Hillyard, S. A. (2011). Neural basis of superior performance of action videogame players in an attention-demanding task. Journal of Neuroscience, 31, 992-998.

Oei, A. C., \& Patterson, M. D. (2013). Enhancing cognition with video games: A multiple game training study. PLoS One, 8, e58546.

Oei, A. C., \& Patterson, M. D. (2015). Enhancing perceptual and attentional skills requires common demands between the action video games and transfer tasks. Frontiers in Psychology, 6, 113.

Pavan, A., Boyce, M., \& Ghin, F. (2016). Action video games improve direction discrimination of parafoveal translational global motion but not reaction times. Perception, 45, 1193-1202.

Petrov, A. A., Dosher, B. A., \& Lu, Z.-L. (2005). The dynamics of perceptual learning: An incremental reweighting model. Psychological Review, 112, 715-743.

Pohl, C., Kunde, W., Ganz, T., Conzelmann, A., Pauli, P., \& Kiesel, A. (2014). Gaming to see: Action video gaming is associated with enhanced processing of masked stimuli. Frontiers in Psychology, 5, 70

Polich, J. (2007). Updating P300: An integrative theory of P3a and P3b. Clinical Neurophysiology, 118, 2128-2148.

Potts, G. F., Liotti, M., Tucker, D. M., \& Posner, M. I. (1996). Frontal and inferior temporal cortical activity in visual target detection: Evidence from high spatially sampled eventrelated potentials. Brain Topography, 9, 3-14.

Potts, G. F., Patel, S. H., \& Azzam, P. N. (2004). Impact of instructed relevance on the visual ERP. International Journal of Psychophysiology, 52, 197-209.

Proverbio, A. M., \& Mangun, G. R. (1994). Electrophysiological and behavioral "costs" and "benefits" during sustained visual-spatial attention. International Journal of Neuroscience, 79, 221-233.

Roelfsema, P. R., van Ooyen, A., \& Watanabe, T. (2010). Perceptual learning rules based on reinforcers and attention. Trends in Cognitive Sciences, 14, 64-71.

Slotnick, S. (2013). The nature of attentional modulation in V1. In S. Slotnick (Ed.), Controversies in cognitive neuroscience (pp. 44-69). New York: Palgrave Macmillan.

Spence, I., \& Feng, J. (2010). Video games and spatial cognition. Review of General Psychology, 14, 92-104.

Verleger, R., Hamann, L. M., Asanowicz, D., \& Śmigasiewicz, K. (2015). Testing the S-R link hypothesis of P3b: The oddball effect on S1-evoked $\mathrm{P} 3$ gets reduced by increased task relevance of S2. Biological Psychology, 108, 25-35.

Vogel, E. K., \& Luck, S. J. (2000). The visual N1 component as an index of a discrimination process. Psychophysiology, 37, 190-203.

Watanabe, T., \& Sasaki, Y. (2015). Perceptual learning: Toward a comprehensive theory. Annual Review of Psychology, 66, 197-221.

West, G. L., Stevens, S. A., Pun, C., \& Pratt, J. (2008). Visuospatial experience modulates attentional capture: Evidence from action video game players. Journal of Vision, 8, 13.

Wu, S., Cheng, C. K., Feng, J., D’Angelo, L., Alain, C., \& Spence, I. (2012). Playing a first-person shooter video game induces neuroplastic change. Journal of Cognitive Neuroscience, 24, 1286-1293.

Wu, S., \& Spence, I. (2013). Playing shooter and driving videogames improves top-down guidance in visual search. Attention, Perception, \& Psychophysics, 75, 673-686. 